\title{
A New Immunological Prognostic Model Based on Immunohistochemistry for Extranodal Natural Killer/T-Cell Lymphoma Patients After Non-Anthracycline-Based Chemotherapy
}

This article was published in the following Dove Press journal:

Cancer Management and Research

\begin{abstract}
Sio Teng Lam ${ }^{1,2, *}$
He Huang '*

Xiaojie Fang'

Zhao Wang (D'

Huangming Hong $\mathbb{D}^{3}$

Quanguang Ren'

Ying Tian'

Suxia $\operatorname{Lin}^{4}$

Tongyu Lin'

'Department of Medical Oncology, Sun Yat-Sen University Cancer Center, State Key Laboratory of Oncology in Southern China, and Collaborative Innovation

Center of Cancer Medicine, Guangzhou, People's Republic of China; ${ }^{2}$ Department of Medical Oncology, Centro Hospitalar Conde De Sao Januario, Macau, People's Republic of China; ${ }^{3}$ Department of Medical Oncology, Sun Yat-Sen Memorial Hospital, Sun Yat-Sen University, Guangzhou, People's Republic of China; ${ }^{4}$ Department of Pathology, Sun Yat-Sen University Cancer Center, Guangzhou, People's Republic of China
\end{abstract}

*These authors contributed equally to this work

Correspondence: Tongyu Lin Department of Medical Oncology, Sun Yat-Sen University Cancer Center, State Key Laboratory of Oncology in Southern China, and Collaborative Innovation

Center of Cancer Medicine, 65I

Dongfeng Road East, Guangzhou,

Guangdong 510060, People's Republic of China

Tel +86-20-87343363

Fax +86-20-87343294

Email tongyulin@hotmail.com
Purpose: Programmed death ligand 1 (PD-L1) has been proposed as an important prognostic factor in many types of cancer. However, the role of predicting the prognosis of PD-L1 in extranodal natural killer/T-cell lymphoma (ENKTL) was controversial. Combining other biomarkers might enhance its predictive power. This study aims to evaluate the prognostic value of PD-L1 in conjunction with tumor-infiltrating FoxP3+Tregs for ENKTL after nonanthracycline-based chemotherapy.

Patients and Methods: A total of 81 patients with ENKTL were included in this study. Clinicopathological characteristics were collected, and prognostic significance of PD-L1 in neoplastic cells (nPD-L1) and tumor-infiltrating FoxP3+Tregs were evaluated.

Results: Patients with nPD-L1-positive had significantly inferior overall survival (OS) and progression-free survival (PFS) compared with nPD-L1-negative (3-year OS, 37.2\% vs $67.3 \%, p=0.014 ; 3$-year PFS, $31.0 \%$ vs $61.8 \%, p=0.010$, respectively). Patients who had low FoxP3+Tregs had significantly inferior OS and PFS compared with high FoxP3+Tregs (3-year OS, $36.4 \%$ vs $63.0 \%, p=0.004$; 3-year PFS, $31.7 \%$ vs $56.3 \%$, p $=0.020$, respectively). The results of multivariate analysis showed that nPD-L1 positivity (HR 6.629, 95\% CI 1.966-22.350, $\mathrm{p}=0.002$ ) and low FoxP3+Tregs (HR 7.317, 95\% CI 2.154-24.855, $\mathrm{p}=0.001$ ) were independent predictors of inferior OS. Using these 2 variables, we constructed a new prognostic model that singled out 3 groups with different risk profiles: group 1, no adverse factors; group 2, 1 adverse factor; and group 3, 2 adverse factors. The 3-year OS rates of group 1, group 2, and group 3 were $93.3 \%, 46.6 \%$ and $20.8 \%$, respectively ( $\mathrm{p}<0.001$ ), and the 3 -year PFS rates were $86.7 \%, 40.8 \%$ and $15.0 \%$, respectively $(\mathrm{p}=0.001$ ). Conclusion: This study is the first to validate the prognostic value of nPD-L1 and tumorinfiltrating FoxP3+Tregs in ENKTL; the new immunological prognostic model might be used to stratify ENKTL patients in clinical trials for new therapeutic strategies.

Keywords: extranodal natural killer/T-cell lymphoma, PD-L1, FoxP3+Tregs, prognosis

\section{Introduction}

Extranodal natural killer/T-cell lymphoma (ENKTL) is defined as an aggressive malignancy that is strongly associated with Epstein-Barr virus (EBV) infection, it is relatively rare in western populations but has a high prevalence in East Asian populations. ${ }^{1}$ ENKTL most commonly presents in the upper-aerodigestive tract, but it can also involve variable extranodal sites. ${ }^{2}$ This disease is often resistant to anthracycline-based chemotherapy, such as $\mathrm{CHOP}^{3}$ Although some studies showed that 
asparaginase-based chemotherapy improved remission and better survival than anthracycline-based chemotherapy, ${ }^{4}$ more than $50 \%$ of patients with advanced disease experience relapse, usually within a year of completing chemotherapy. ${ }^{5}$ Therefore, new therapeutic approaches based on molecular oncogenic mechanisms are urgently required.

The tumor immune microenvironment plays an important role in tumor development and progression through interactions between tumor cells and the immune system. Programmed death ligand 1 (PD-L1), as an immunomodulatory cell-surface glycoprotein, is expressed on antigenpresenting cells and can be induced on various tumor cells within the tumor microenvironment. ${ }^{6-9}$ Tumor cell expression of PD-L1 results in tumor-specific T cell inactivity through engagement of PD-1-expressing T cells and serves as a way to evade immune surveillance and the immune response. ${ }^{10,11}$ It has been shown that PD-L1 expression on tumor cells is related to a poor prognosis in many types of solid tumors. ${ }^{12-17}$ However, the results regarding the prognostic significance of PD-L1 in ENKTL are conflicting. ${ }^{18-22}$ Based on these observations, the role of predicting the prognosis of PD-L1 has not been fully elucidated, and its use in combination with other biomarkers might enhance its predictive power.

FOXP3, a forkhead helix transcription factor, is now recognized as a specific marker for regulatory T-cells (Tregs) ${ }^{23}$ and appears to function as a master regulator in the development and control of Tregs. ${ }^{24,25}$ FoxP3+Tregs are an important component of the lymphoma immune microenvironment. The prognostic effect of FoxP3+Tregs remains debatable because it is associated with a poor prognosis in various solid malignancies. ${ }^{26-28}$ whereas it has a better prognosis for hematologic malignancies. ${ }^{29-31}$ However, little is known about the prognostic value of FoxP3+Tregs in patients with ENKTL.

PD-L1 was found to have a pivotal role in enhancing and sustaining FoxP3 expression, regulating FoxP3+Treg development and sustaining FoxP3+Treg function. ${ }^{32,33}$ However, knowledge of the prognostic role of neoplastic PD-L1 (nPDL1) expression in conjunction with tumor-infiltrating FoxP3 +Tregs in ENKTL is limited. Therefore, in this study, we investigated the prognostic value of nPD-L1 combined with tumor-infiltrating FoxP3+Tregs in ENKTL patients after receiving non-anthracycline-based chemotherapy.

\section{Materials and Methods}

\section{Patients}

A total of 365 consecutive patients newly diagnosed with ENKTL according to the 2008 WHO criteria of lymphoma between 2008 and 2017 were collected from Sun Yat-sen University Cancer Center. Cases with a relapsed course, previous anti-cancer treatment and inadequate/insufficient samples were excluded. A total of 81 patients with formalin-fixed, paraffin-embedded (FFPE) samples available, complete clinicopathologic and follow-up data were analyzed in this study. Patient clinical information such as demographic features, performance status, B symptoms, serum lactate dehydrogenase (LDH), stage, International prognostic index (IPI), ${ }^{34}$ Korean prognostic index (KPI), ${ }^{35}$ the prognostic index of natural killer lymphoma (PINK) score, ${ }^{36}$ nasal and nonnasal types, treatment modalities and treatment response were recorded. All tissue samples were acquired at initial presentation prior to treatment. This work was approved by the ethics committee of Sun Yatsen University Cancer Center. Written informed consent were provided from all patients prior to collecting patient tissue samples and clinical information.

\section{Immunohistochemistry}

All the diagnoses were confirmed by two experienced pathologists after reviewing hematoxylin and eosin-stained tissue sections, immunohistochemistry (IHC) results and clinical data. IHC examinations including CD3, CD56, T-cell intracytoplasmic antigen-1 (TIA-1), CD4, PD1, CD30 and in situ hybridization for EBV-encoded small RNAs (EBERs) were performed on sections of 4- $\mu \mathrm{m}$ thickness. Sections cut from FFPE blocks $4-\mu \mathrm{m}$ thick underwent deparaffinization and rehydration through changes in xylene, graded ethanol and water. Antigen retrieval was performed with microwave pressure-cooking at $1000 \mathrm{~W}$ for $2.5 \mathrm{mins}$ in trisethylenediaminetetraacetic acid (EDTA) buffer ( $\mathrm{pH}$ 9) before staining with each primary antibody. After cooling and washing with buffer, $3 \%$ hydrogen peroxide solution was used for blocking endogenous peroxidase in tissues for 2 mins. Then, slides were incubated with an anti-PD-L1 mouse monoclonal antibody (UMAB228 clone, ZM-0170, 1:100 dilution) and with a mouse anti-FoxP3 monoclonal antibody (236A/E7 clone, Abcam, 1:100 dilution) in Dako antibody diluent at $4^{\circ} \mathrm{C}$ overnight. Subsequently, the slides were serially rinsed and incubated with secondary antibodies at $37^{\circ} \mathrm{C}$ in an incubator for 20 mins. Dako Real Envision 3,3'diaminobenzidine (DAB) was applied for 1-2 mins for the visualization of antigen-antibody binding, and the sections were counterstained with Mayer hematoxylin, dehydrated with ethanol, and coverslipped for evaluation. The slides were reviewed by two experienced pathologists independently who were blinded to the clinical data. The expression 
of PD-L1 was scored semiquantitatively based on the proportion of staining regardless of staining intensity. A representative tumor area was defined as having tumor cells in $>80 \%$ of the area. A tumor area was avoided if it showed marked necrosis in $>20 \%$ of the area or had an ulcer and inflamed granulation tissue. Four high-power fields (HPFs, 400× magnification level) of representative areas with similar total cell numbers were evaluated for the expression of PD-L1 of tumor cells and the number of tumorinfiltrating FoxP3+Tregs. In cases of disagreement, a consensus was reached by two blinded observers who reexamined the slides with a two-headed microscope.

\section{Treatment and Response Evaluation}

Patients received one of the following initial treatment modalities: (1) chemotherapy (CT) alone or (2) CT combined with RT. All patients received non-anthracycline-based chemotherapy. The treatment response was evaluated according to standard response criteria. ${ }^{37}$ The chemotherapeutic regimens used were as following: (1) GELOX (gemcitabine, L-asparaginase and oxaliplatin); (2) SMILE (corticosteroid, methotrexate, ifosfamide, L-asparaginase, and etoposide).

\section{Statistical Analysis}

Categoric data were compared via Pearson's chi-square or Fisher's test, whereas continuous variables were compared via Mann-Whitney and Kruskal-Wallis tests. Optimal cutoff values of nPD-L1 level and FoxP3+Treg level for predicting survival were determined using receiver operating characteristics (ROC) curve analysis. Progression-free survival (PFS) was defined as the period of time from the date of initial diagnosis to the date of disease progression or death. Overall survival (OS) was defined as the period of time from the date of initial diagnosis to the date of death or last follow-up. OS and PFS were compared using the Kaplan-Meier method with a Log rank test. The multivariate analysis of the variables predicting prognosis was performed by logistic regression. The Statistical Package for Social Sciences software, version 20.0 (IBM, USA) was used for statistical analyses, and two-sided $\mathrm{p}$ values less than 0.05 were considered significant based on a twosided statistical analysis.

\section{Results}

\section{Clinical Characteristics}

Table 1 summarizes the main clinical and histologic features of the 81 patients at diagnosis. Briefly, more male
Table I Main Clinical and Histopathologic Features of 8 I Patients

\begin{tabular}{|c|c|}
\hline Characteristics & Patients, $n=81$, No. (\%) \\
\hline Male/Female & $59(72.8) / 22(27.2)$ \\
\hline Median age(range),years & $45(16-79)$ \\
\hline \multicolumn{2}{|l|}{ ECOG PS } \\
\hline $0-1$ & $73(90.1)$ \\
\hline$\geq 2$ & $8(9.9)$ \\
\hline \multicolumn{2}{|l|}{ B symptoms } \\
\hline yes & $44(54.3)$ \\
\hline no & $37(45.7)$ \\
\hline \multicolumn{2}{|l|}{ LDH level } \\
\hline Normal & $64(79.0)$ \\
\hline Increased & $17(21.0)$ \\
\hline \multicolumn{2}{|l|}{ Ann Arbor stage } \\
\hline $\mathrm{I} / \mathrm{II}$ & $39(48.1)$ \\
\hline III/IV & $42(51.9)$ \\
\hline \multicolumn{2}{|l|}{ IPI } \\
\hline $0-1$ & $35(43.2)$ \\
\hline$\geq 2$ & $46(56.8)$ \\
\hline \multicolumn{2}{|l|}{ KPI } \\
\hline $0-1$ & $33(40.7)$ \\
\hline$\geq 2$ & $48(59.3)$ \\
\hline \multicolumn{2}{|l|}{ PINK } \\
\hline low-risk & $23(28.4)$ \\
\hline intermediate-risk & $24(29.6)$ \\
\hline high-risk & $34(42.0)$ \\
\hline UAT/non-UAT & $66(81.5) / 15(18.5)$ \\
\hline $\mathrm{CR}$ after primary treatment & $46(56.8)$ \\
\hline \multicolumn{2}{|l|}{ Therapy pattern } \\
\hline $\mathrm{CT}$ & $44(54.3)$ \\
\hline $\mathrm{CT}+\mathrm{RT}$ & $37(45.7)$ \\
\hline \multicolumn{2}{|l|}{ Chemotherapy regimen } \\
\hline GELOX & $51(63.0)$ \\
\hline SMILE & $30(37.0)$ \\
\hline
\end{tabular}

Abbreviations: ECOG PS, Eastern Cooperative Oncology Group performance status; LDH, lactate dehydrogenase; IPI, International Prognostic Index; KPI, Korean prognostic index; PINK, prognostic index of natural killer lymphoma; UAT, upper aerodigestive tract; $\mathrm{CR}$, complete remission; RT, radiotherapy; $\mathrm{CT}$, chemotherapy; GELOX, gemcitabine, L-asparaginase, and oxaliplatin; SMILE, corticosteroid, methotrexate, ifosfamide, L-asparaginase, and etoposide.

patients than female patients were included (72.8\%). More than half of the patients had advanced-stage disease $(51.9 \%)$. The most frequently involved sites were the upper aerodigestive tract (UAT) $(81.5 \%)$. More than half of the patients had high-risk IPI scores $(56.8 \%$ had an IPI score of $\geq 2$ ), and high-risk KPI scores (59.3\% had a KPI score of $\geq 2$ ) and were in intermediate- and high-risk groups based on PINK scores (71.6\%). Among the various 
non-anthracycline-based chemotherapy regimens, GELOX (63.0\%) was the most commonly used.

\section{Pathological and Immunophenotypic Characteristics}

Only 3 of the 78 patients (3.8\%) expressed PD-1 in tumorinfiltrating immune cells, however, none of the patients expressed PD-1 in tumor cells. CD3 was positive in 76 of 80 cases $(95.0 \%), \mathrm{CD} 4$ was positive in 8 of 42 cases (19.0\%). The percentage of PD-L1-positive malignant cells varied widely from $0-70 \%$, with a median value of $10 \%$ (Figure 1A and B). Based on the ROC curve for clinical outcome, the optimal cutoff value of neoplastic PD-L1 (nPD-L1) positive was $10 \%$, which makes nPD-L1 positive defined as $10 \%$ or more of lymphoma cells stained and allowed groups nPD-L1-positive group and nPD-L1 negative group to be distinguished. The number of FoxP3+Tregs varied widely from $0-468.25 / \mathrm{HPF}$ (400× magnification), with a median value of 52.5/HPF (Figure $1 \mathrm{C}$ and D). Based on the ROC curve for clinical outcome, the optimal cutoff value of FoxP3+Tregs was approximately 46/HPF,

\section{A}

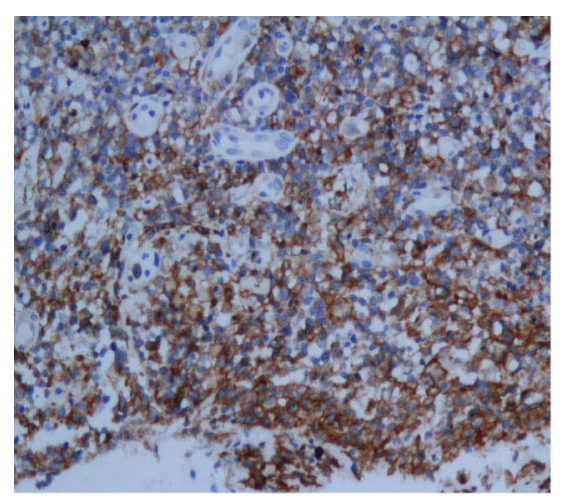

C

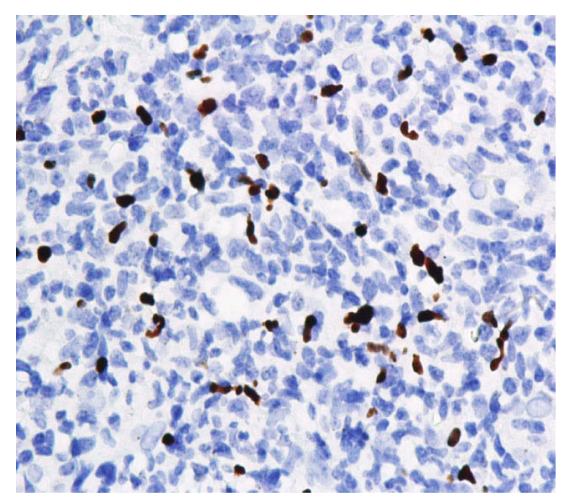

which allowed groups with low and high levels of FoxP3 + Tregs to be distinguished.

\section{Clinicopathological Comparison Between nPD-LI Positivity and Negativity}

In our study, the nPD-L1-positive group showed a trend toward an older median age ( $48 \mathrm{y}$ vs $42 \mathrm{y}, \mathrm{p}=0.066$ ) and higher PINK score $(45.4 \%$ vs $37.8 \%, \mathrm{p}=0.071)$ and a trend toward a lower CR rate after initial treatment $(47.7 \%$ vs $67.6 \%, \mathrm{p}=0.073$ ) (Table 2). The high FoxP3+Tregs group had more female patients ( $36.4 \%$ vs $16.2 \%, \mathrm{p}=0.046)$ and fewer patients with a high PINK score $(29.5 \%$ vs $56.7 \%$, $\mathrm{p}=0.021$ ) than the low FoxP3+Treg group, both of which were significant (Table 2).

\section{Survival Analysis According to the Expression of nPD-LI and FoxP3+Tregs}

The median follow-up period of the entire cohort was 28.9 months (range 1-129 months). The 3-year PFS and 3-year OS were $45.1 \%$ and $51.0 \%$, respectively. Patients with

B

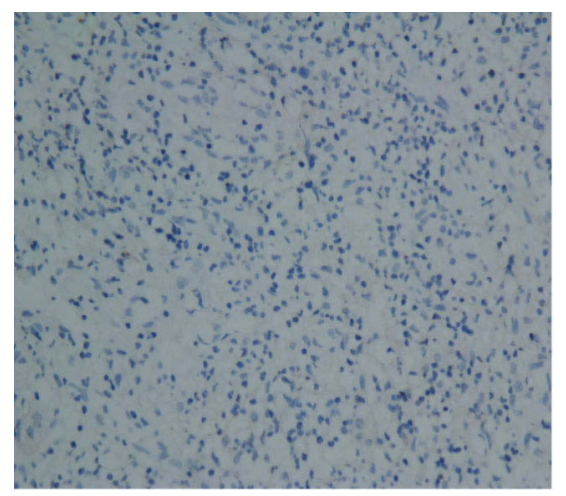

D

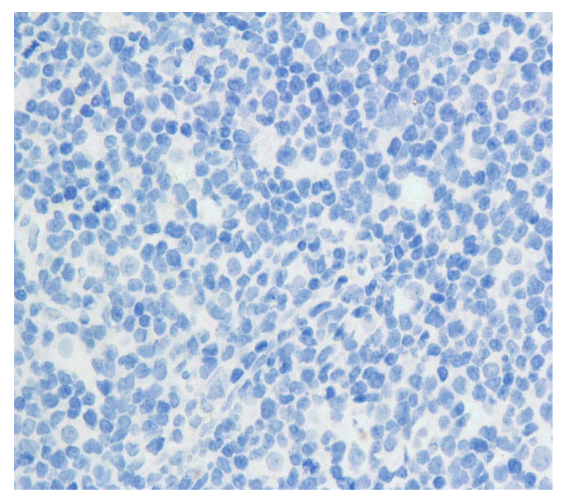

Figure I Representative immunohistochemical analysis of PD-LI expression in neoplastic cells. (A) PD-LI positive in neoplastic cells ( $\times 200)$; (B) PD-LI negative in neoplastic cells $(\times 200)$. Representative immunohistochemical analysis of tumor-infiltrating FoxP3+Tregs in ENKTL. (C) High tumor-infiltrating FoxP3+Tregs $(\times 200)$; (D) Low tumor-infiltrating FoxP3+Tregs $(\times 200)$. 
Table 2 Correlation of Neoplastic PD-LI Expression and FoxP3+ Tregs with Clinicopathological Features

\begin{tabular}{|c|c|c|c|c|c|c|}
\hline Characteristic & $\begin{array}{l}\text { nPD-LI Positive } \\
(n=44)\end{array}$ & $\begin{array}{l}\text { nPD-LI Negative } \\
(n=37)\end{array}$ & P value & $\begin{array}{l}\text { High FoxP3+ Tregs } \\
(n=44)\end{array}$ & $\begin{array}{l}\text { Low FoxP3+ } \\
\text { Tregs }(n=37)\end{array}$ & $P$ value \\
\hline $\begin{array}{l}\text { Male/Female } \\
\text { Median age(range),years }\end{array}$ & $\begin{array}{l}29(65.9) / 15(34.1) \\
48(16-79)\end{array}$ & $\begin{array}{l}30(81.1) / 7(18.9) \\
42(16-70)\end{array}$ & $\begin{array}{l}0.142 \\
0.066\end{array}$ & $\begin{array}{l}28(63.6) / 16(36.4) \\
45.5(16-70)\end{array}$ & $\begin{array}{l}31(83.8) / 6(16.2) \\
45.0(16-79)\end{array}$ & $\begin{array}{l}0.042^{*} \\
0.435\end{array}$ \\
\hline $\begin{array}{l}\text { ECOG/PS } \\
0-1 \\
\geq 2\end{array}$ & $\begin{array}{l}39(88.6) \\
5(11.4)\end{array}$ & $\begin{array}{l}34(91.9) \\
3(8.1)\end{array}$ & 0.721 & $\begin{array}{l}4 I(93.2) \\
3(6.8)\end{array}$ & $\begin{array}{l}32(86.5) \\
5(13.5)\end{array}$ & 0.314 \\
\hline $\begin{array}{l}\text { B symptoms } \\
\text { yes } \\
\text { no }\end{array}$ & $\begin{array}{l}21(47.7) \\
23(52.3)\end{array}$ & $\begin{array}{l}16(43.2) \\
21(56.8)\end{array}$ & 0.823 & $\begin{array}{l}24(54.5) \\
20(45.5)\end{array}$ & $\begin{array}{l}20(54.1) \\
17(45.9)\end{array}$ & 0.965 \\
\hline $\begin{array}{l}\text { LDH level } \\
\text { Normal } \\
\text { Increased }\end{array}$ & $\begin{array}{l}35(79.5) \\
9(20.5)\end{array}$ & $\begin{array}{l}31(83.8) \\
6(16.2)\end{array}$ & 0.625 & $\begin{array}{l}36(81.8) \\
8(18.2)\end{array}$ & $\begin{array}{l}30(81.1) \\
7(18.9)\end{array}$ & 0.932 \\
\hline $\begin{array}{l}\text { Ann Arbor stage } \\
\text { I/II } \\
\text { III/ IV }\end{array}$ & $\begin{array}{l}21(47.7) \\
23(52.3)\end{array}$ & $\begin{array}{l}18(48.6) \\
19(51.4)\end{array}$ & 0.934 & $\begin{array}{l}22(50.0) \\
22(50.0)\end{array}$ & $\begin{array}{l}17(45.9) \\
20(54.1)\end{array}$ & 0.716 \\
\hline $\begin{array}{l}\text { IPI } \\
\quad 0-\text { I } \\
\geq 2\end{array}$ & $\begin{array}{l}16(36.4) \\
28(63.6)\end{array}$ & $\begin{array}{l}19(51.4) \\
18(48.6)\end{array}$ & 0.175 & $\begin{array}{l}19(43.2) \\
25(56.8)\end{array}$ & $\begin{array}{l}16(43.2) \\
21(56.8)\end{array}$ & 0.996 \\
\hline $\begin{array}{l}\mathrm{KPI} \\
\quad 0-1 \\
\geq 2\end{array}$ & $\begin{array}{l}19(43.2) \\
25(56.8)\end{array}$ & $\begin{array}{l}14(37.8) \\
23(62.2)\end{array}$ & 0.626 & $\begin{array}{l}17(38.6) \\
27(61.4)\end{array}$ & $\begin{array}{l}16(43.3) \\
21(56.7)\end{array}$ & 0.674 \\
\hline $\begin{array}{l}\text { PINK } \\
\text { low-risk } \\
\text { Intermediate-risk } \\
\text { High-risk }\end{array}$ & $\begin{array}{l}8(18.2) \\
16(36.4) \\
20(45.4)\end{array}$ & $\begin{array}{l}15(40.6) \\
8(21.6) \\
14(37.8)\end{array}$ & 0.071 & $\begin{array}{l}13(29.5) \\
18(41.0) \\
13(29.5)\end{array}$ & $\begin{array}{l}10(27.1) \\
6(16.2) \\
21(56.7)\end{array}$ & $0.021^{*}$ \\
\hline $\begin{array}{l}\text { UAT/non-UAT } \\
\text { CR after primary treatment }\end{array}$ & $\begin{array}{l}33(75.0) / 11(25.0) \\
21(47.7) / 23(52.3)\end{array}$ & $\begin{array}{l}33(89.2) / 4(10.8) \\
25(67.6) / 12(32.4)\end{array}$ & $\begin{array}{l}0.151 \\
0.073\end{array}$ & $\begin{array}{l}37(84.1) / 7(15.9) \\
27(47.7) / 17(52.3)\end{array}$ & $\begin{array}{l}29(78.3) / 8(21.7) \\
19(67.6) / 18(32.4)\end{array}$ & $\begin{array}{l}0.510 \\
0.365\end{array}$ \\
\hline $\begin{array}{l}\text { Therapy pattern } \\
\qquad C T \\
C T+R T\end{array}$ & $\begin{array}{l}25(56.8) \\
19(43.2)\end{array}$ & $\begin{array}{l}19(51.3) \\
18(48.7)\end{array}$ & 0.623 & $\begin{array}{l}26(59.1) \\
18(42.9)\end{array}$ & $\begin{array}{l}18(48.6) \\
19(51.4)\end{array}$ & 0.347 \\
\hline $\begin{array}{l}\text { Chemotherapy regimen } \\
\text { GELOX } \\
\text { SMILE }\end{array}$ & $\begin{array}{l}31(70.5) \\
13(29.5)\end{array}$ & $\begin{array}{l}20(54.1) \\
17(45.9)\end{array}$ & 0.387 & $\begin{array}{l}27(61.4) \\
17(38.6)\end{array}$ & $\begin{array}{l}24(64.9) \\
13(35.1)\end{array}$ & 0.384 \\
\hline
\end{tabular}

Notes: $* P<0.05$, the difference was statistically significant.

Abbreviations: ECOG PS, Eastern Cooperative Oncology Group performance status; LDH, lactate dehydrogenase; IPI, International Prognostic Index; KPI, Korean prognostic index; PINK, prognostic index of natural killer lymphoma; UAT, upper aerodigestive tract; CR, complete remission; RT, radiotherapy; CT, chemotherapy; GELOX, gemcitabine, L-asparaginase, and oxaliplatin; SMILE, corticosteroid, methotrexate, ifosfamide, L-asparaginase, and etoposide.

nPD-L1-positive had significantly inferior OS and PFS compared with patients with nPD-L1-negative (3-year OS, 37.2\% vs $67.3 \%, \mathrm{p}=0.014$; 3 -year PFS, $31.0 \%$ vs $61.8 \%$, $\mathrm{p}=0.010$, respectively) (Figure $2 \mathrm{~A}$ and $\mathrm{B}$ ). Patients who had low FoxP3+Tregs had significantly inferior OS and PFS compared with high FoxP3+Tregs (3-year OS, 36.4\% vs 63.0\%, $\mathrm{p}=0.004$; 3 -year PFS, $31.7 \%$ vs $56.3 \%, \mathrm{p}=0.020$, respectively) (Figure $2 \mathrm{C}$ and $\mathrm{D}$ ).
In univariate analysis, factors predicting inferior OS included advanced stage (Ann Arbor stage III/IV $\mathrm{p}=0.029)$, nPD-L1 positivity $(\mathrm{p}=0.014)$ and low FoxP3 + Tregs $(\mathrm{p}=0.005)$. In multivariate analysis, nPD-L1 positivity (HR 6.629, 95\% CI 1.966-22.350, $\mathrm{p}=0.002$ ) and low FoxP3+Tregs (HR 7.317, 95\% CI 2.154$24.855, \mathrm{p}=0.001)$ were independent predictors of inferior OS (Table 3). 


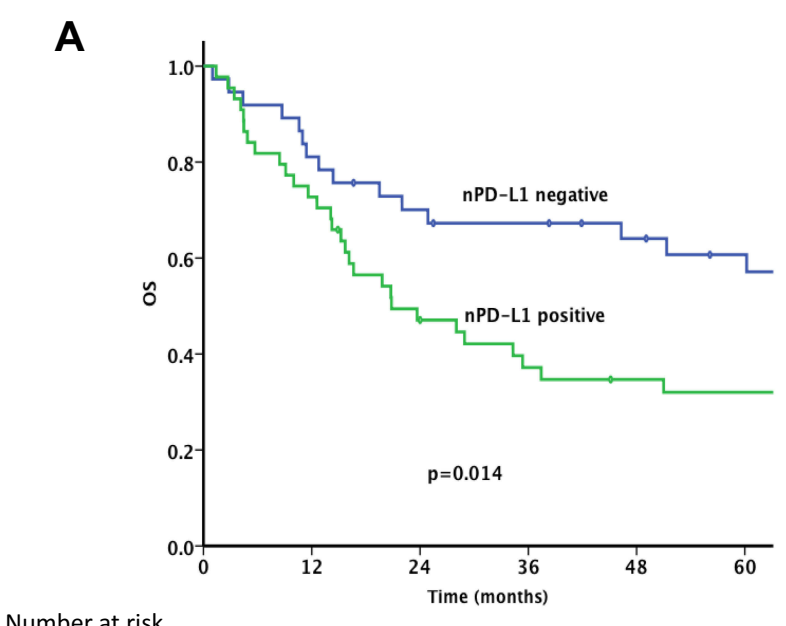

Number at risk
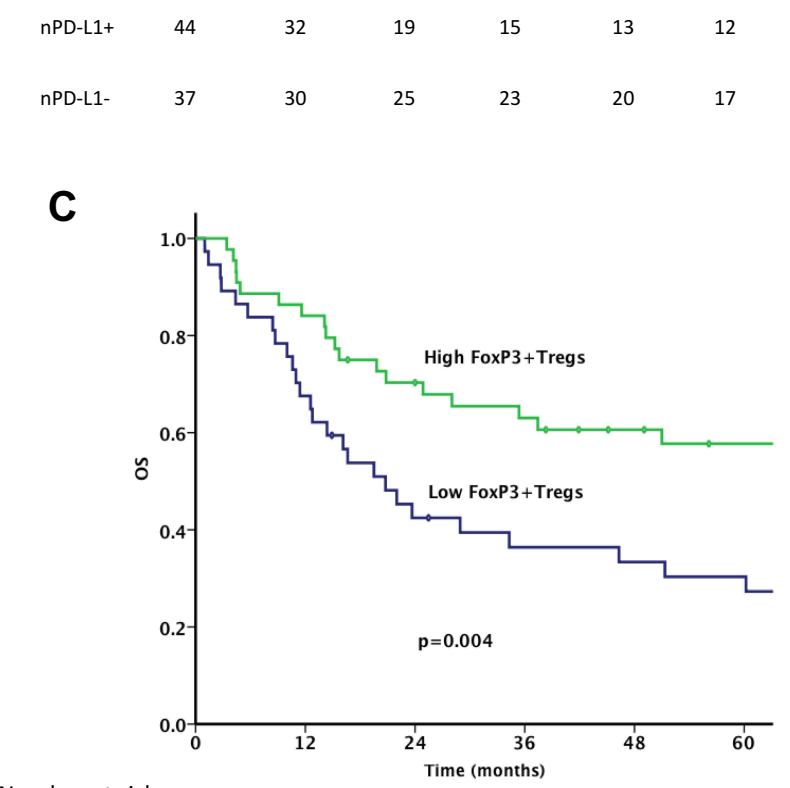

Number at risk

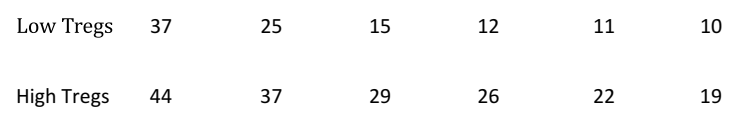

B

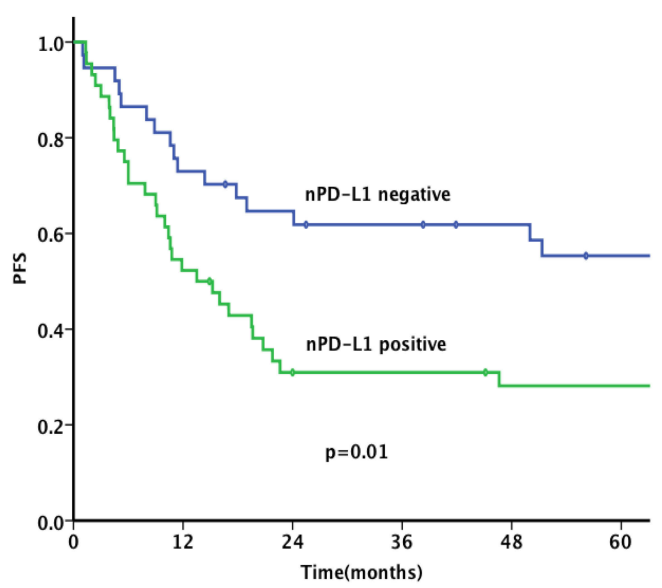

Number at risk

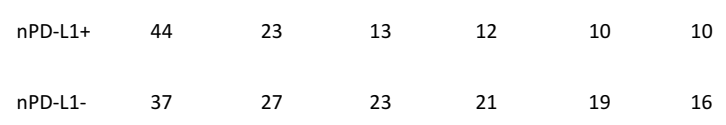

D

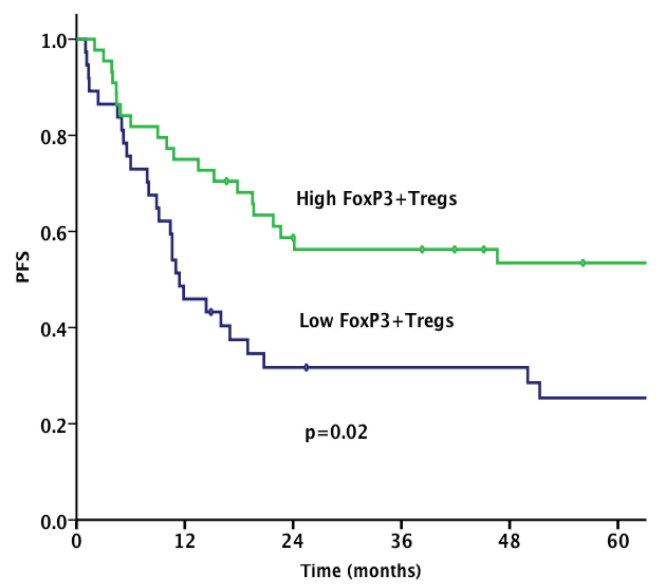

Number at risk

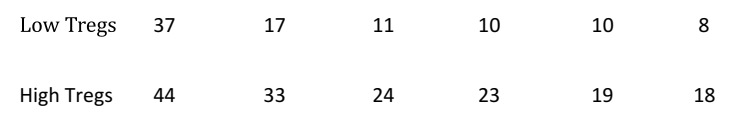

Figure 2 Survival of patients with nPD-LI positive and nPD-LI negative. (A) OS; (B) PFS. Survival of patients with high FoxP3+ Tregs and low FoxP3+Treg. (C) OS; (D) PFS.

Univariate survival analysis revealed that the male sex $(\mathrm{p}=0.039)$, presence of systemic $\mathrm{B}$ symptoms $(\mathrm{p}=0.016)$, advanced stage (Ann Arbor stage III/IV $\mathrm{p}=0.026$ ), bone marrow involvement $(\mathrm{p}=0.017)$, regional lymphadenopathy involvement $(\mathrm{p}=0.006), n P D-L 1$ positivity $(\mathrm{p}=0.016)$ and low FoxP3+Tregs $(\mathrm{p}=0.022)$ were significantly associated with a poor PFS. Then, a multivariate analysis was performed including all variables found to be significant in the univariate analysis, which identified nPD-L1 positivity (HR 5.266, 95\% CI 1.668-16.626, $\mathrm{p}=0.005$ ) and low FoxP3 + Tregs (HR 3.598, 95\% CI 1.127-11.493, $\mathrm{p}=0.031$ ) as independent prognostic factors for poor PFS (Table 3).
Using these two variables (nPD-L1 and FoxP3+Tregs), we constructed a new prognostic model that stratified the patients into 3 groups with different risk profiles: group 1, no adverse factors; group 2, 1 adverse factor; and group 3, 2 adverse factors. The 3 -year OS rates of group 1, group 2, and group 3 were $93.3 \%, 46.6 \%$ and $20.8 \%$, respectively $(\mathrm{p}<0.001)$ (Figure $3 \mathrm{~A}$ ), and 3-year PFS rates were $86.7 \%$, $40.8 \%$ and $15.0 \%$, respectively $(\mathrm{p}=0.001)$ (Figure $3 \mathrm{~B}$ ).

Additionally, we used a ROC analysis to compare the sensitivity and specificity of survival prediction. Our new prognostic model showed a better performance in predicting survival than the PINK model with regard to OS (our 
Table 3 Univariate and Multivariate Analysis of Factors Associated with Overall Survival and Progression-Free Survival

\begin{tabular}{|c|c|c|c|c|c|c|}
\hline \multirow[t]{3}{*}{ Clinical Characteristic } & \multicolumn{3}{|l|}{ OS } & \multicolumn{3}{|l|}{ PFS } \\
\hline & \multirow{2}{*}{$\begin{array}{l}\begin{array}{l}\text { Univariate } \\
\text { Analysis }\end{array} \\
\text { P value }\end{array}$} & \multicolumn{2}{|l|}{ Multivariate Analysis } & \multirow{2}{*}{$\begin{array}{l}\begin{array}{l}\text { Univariate } \\
\text { Analysis }\end{array} \\
\text { P value }\end{array}$} & \multicolumn{2}{|l|}{ Multivariate Analysis } \\
\hline & & HR (95\% Cl) & $P$ value & & HR (95\% Cl) & P value \\
\hline Gender,male & 0.169 & & & $0.039 *$ & & \\
\hline Age $>60$ & 0.063 & & & 0.149 & & \\
\hline $\mathrm{ECOG} / \mathrm{PS} \geq 2$ & 0.258 & & & 0.552 & & \\
\hline B symptoms & 0.112 & & & $0.016^{*}$ & 3.047 (0.989-9.387) & 0.052 \\
\hline $\mathrm{LDH} \geq 245 \mathrm{U} / \mathrm{L}$ & 0.346 & & & 0.208 & & \\
\hline Ann Arbor stage(III/IV) & $0.029 *$ & $4.148(0.980-17.562)$ & 0.053 & $0.026 *$ & $6.161(0.697-54.501)$ & 0.102 \\
\hline Bone marrow involvement & 0.420 & & & $0.017^{*}$ & & \\
\hline Regional LN involvement & 0.303 & & & $0.006 *$ & & \\
\hline UAT & 0.133 & & & 0.199 & & \\
\hline nPD-LI+ & $0.014^{*}$ & $6.629(1.966-22.350)$ & $0.002 *$ & $0.016 *$ & $5.266(1.668-16.626)$ & $0.005^{*}$ \\
\hline FoxP3+Tregs(low) & $0.005^{*}$ & $7.317(2.154-24.855)$ & $0.001 *$ & $0.022^{*}$ & $3.598(1.127-11.493)$ & $0.031 *$ \\
\hline
\end{tabular}

Notes: ${ }^{*} \mathrm{P}<0.05$, the difference was statistically significant. The multivariate analysis was performed by logistic regression.

Abbreviations: OS, overall survival; PFS, progression-free survival; ECOG PS, Eastern Cooperative Oncology Group performance status; LDH, lactate dehydrogenase; LN, lymph node; UAT, upper aerodigestive tract.

model ROC area, 0.741; 95\% CI, 0.630-0.851; PINK ROC area, 0.697; 95\% CI, 0.583-0.811).

\section{Discussion}

In this study, we identified two risk factors for PD-L1 expression in tumor cells and tumor-infiltrating FoxP3 +Tregs among various clinical parameters that were

A

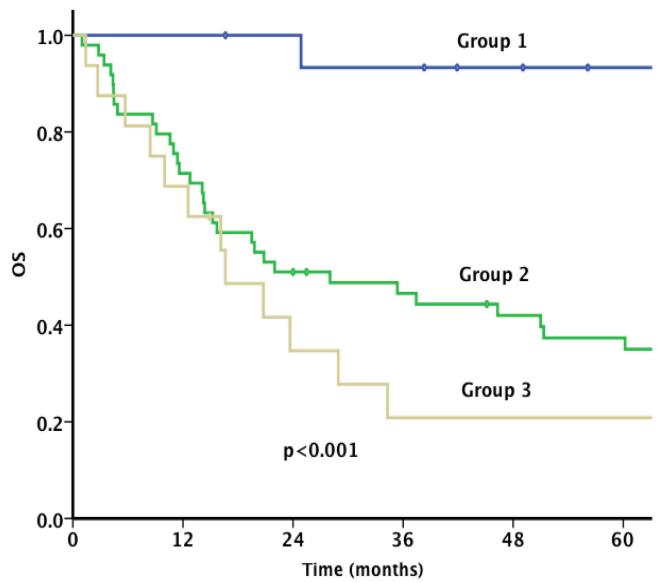

Number at risk

$\begin{array}{ccccccc}\text { Group 1 } & 16 & 15 & 14 & 14 & 12 & 10 \\ \text { Group 2 } & 49 & 35 & 24 & 21 & 18 & 15 \\ \text { Group 3 } & 16 & 11 & 5 & 3 & 3 & 3\end{array}$

identified as being independent predictors of OS and PFS. Our new immunological prognostic model that included these two factors could stratify the prognosis of ENKTL patients after non-anthracycline-based chemotherapy with statistical significance. Furthermore, our method uses immunohistochemistry, which is inexpensive and simple to perform in clinical studies and in general

Figure 3 Survival of patients with combined nPD-LI and FoxP3+Tregs. (A) OS; (B) PFS.

B

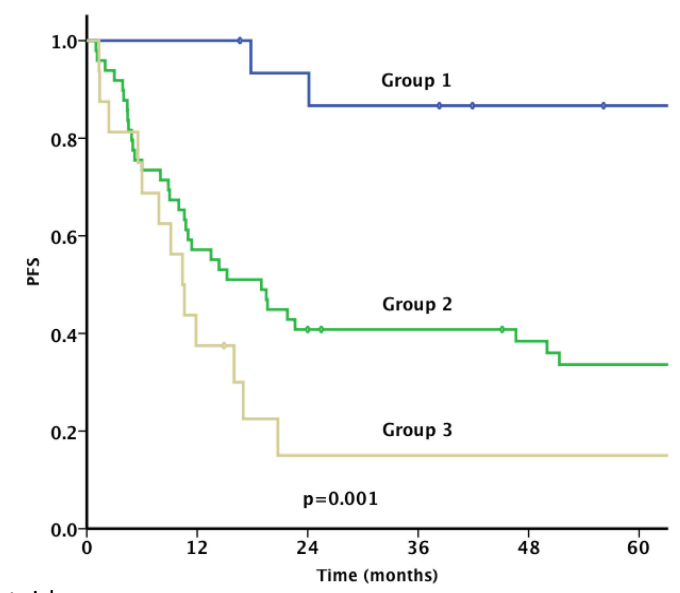

Number at risk

$\begin{array}{ccccccc}\text { Group 1 } & 16 & 15 & 14 & 13 & 11 & 10 \\ \text { Group 2 } & 49 & 28 & 20 & 18 & 16 & 14 \\ \text { Group 3 } & 16 & 6 & 2 & 2 & 2 & 2\end{array}$


practice. Our research provides support for the use of these biomarkers as a supplement for predicting prognosis.

Previous studies have shown that PD-L1 expression on tumor cells is associated with poor prognosis in various solid malignant tumors and some types of hematologic malignancies. ${ }^{12-17}$ However, the results regarding the role of PD-L1 expression in ENKTL remain controversial. Kim and his colleagues found that PD-L1 expression was the only significant independent predictor for longer OS in patients with advanced stage ENKTL. ${ }^{18}$ Another recent study also found that ENKTL patients with PD-L1 positivity in tumor cells had a trend toward improved OS compared with the negative control. ${ }^{21}$ Contrary to these results, Bi et al and Muhamad et al found that PD-L1 expression in lymphoma cell tissue exhibited remarkably worse OS in ENKTL patients, ${ }^{19}$ which was similar to the results of our study. Therefore, a single biomarker of PDL1 for predicting the prognosis of ENKTL patients might have some limitations. More studies are needed to elucidate the role of PD-L1 or the incorporation of other biomarkers to PD-L1 to gain good prognostic capacity in ENKTL patients.

Currently, the mechanism of upregulation of PD-L1 expression in ENKTL tumor cells remains unclear. Previous data have shown that the expression of PD-L1 in tumor cells could be upregulated by 9 p24.1 amplification in classical Hodgkin's lymphomas (HL) and diffuse large B cell lymphoma (DLBCL). ${ }^{38,39}$ Moreover, Green et al demonstrated that PD-L1 is expressed in HL- and EBV-positive posttransplant lymphoproliferative disorders (PTLD) as a result of latent membrane protein 1 (LMP1)mediated JAK/STAT-dependent promoter and AP-1-associated enhancer activity. ${ }^{38}$ ENKTL, which is closely related to EBV infection, is thought to be related to the expression of PD-L1 in tumor cells of ENKTL and LMP1. In a recent study of NK cell lines, PD-L1 is upregulated by EBV-driven LMP1 through the NF- $\mathrm{BB}$ pathway. ${ }^{19}$ The mechanism of PD-L1 expression on tumor cells affecting the prognosis of ENKTL remains unclear. It is thought that the PD-1/PD-L1 pathway might contribute to a poor prognosis in ENKTL patients with PD-L1 expression on tumor cells. The expression of PD-L1 in tumor cells may engage PD-1 receptors on tumor-infiltrating T cells, induce PD-1 signaling and associated T-cell "exhaustion", and mediate tumors to escape the host immune response. ${ }^{40}$ Therefore, it is speculated that PD-1/PD-L1 blockade may benefit ENKTL patients. In a retrospective study, Kwong YL et al reported that PD1 blockade with pembrolizumab is effective in relapsed or refractory NK/T-cell lymphoma failing L-asparaginase regimens, which provide proof-ofconcept data that the PD-L1/PD1 axis is highly relevant in this malignancy. ${ }^{41}$

PD-L1 was found to have a pivotal role in enhancing and sustaining FoxP3 expression, regulating FoxP3+Treg development and sustaining FoxP3+Treg function. ${ }^{32,33}$ In this study, we demonstrated that low frequency FoxP3+Treg infiltration in the tumor microenvironment was an independent prognostic factor for poor outcome in patients with ENKTL, which is similar to the results reported in other hematologic malignancies, such as follicular lymphomas, DLBCL and HL. ${ }^{29-31}$ However, many studies showed that a low density of FoxP3+Tregs infiltrating the tumor microenvironment correlated with improved clinical outcomes in various human solid malignancies. ${ }^{23,26-28}$ This evidence suggests that the role of FoxP3+Tregs in the pathogenesis of solid tumors and hematological malignancies is different. FoxP3+Tregs may represent important lymphoma/host microenvironment modulators that participate in the regulation of the host immune response and biologic behavior of ENKTL. As important independent immune biomarkers, our study combined nPD-L1 and tumor-infiltrating FoxP3 +Tregs to form a new immunological prognostic model that yielded prognostic stratification with significance in ENKTL patients. This result suggested that these two biomarkers might serve as a supplement for each other when combined to predict prognosis in ENKTL patients. Moreover, the PINK model has been found to be useful at predicting outcomes in patients with ENKTL, ${ }^{36}$ but our new prognostic model showed similar predictive accuracy as the PINK model, which indicated that our model successfully reflects the clinical outcome in ENKTL patients. However, how PD-LI expression on tumor cells and tumor-infiltrating FoxP3+Tregs counteract and impact the development of ENKTL remains unclear and should be explored in future studies.

There are some limitations to our study. First, being a retrospective study utilizing registry data is an inherent limitation. Second, the sample size is relatively small, which may limit the power to detect differences between groups.Third, circulating EBV-DNA was not included as variables in our study due to patients series that are collected over long periods and some of which are without EBV-DNA result. Therefore, further prospective studies including larger samples are needed to validate our results. 


\section{Conclusion}

In conclusion, our new immunological prognostic model based on immunohistochemistry could stratify the prognosis of ENKTL patients after non-anthracycline-based chemotherapy and might be used to stratify patients in clinical trials for new therapeutic strategies or riskadapted therapies.

\section{Acknowledgments}

This work was supported by grants from the Funds for International (Regional) Cooperation and Exchange of the Natural Science Foundation of China/NSFC-FDCT (81661168011), the Guangdong Science and Technology Department (2017B020227002, 2017A020215030).

\section{Disclosure}

The authors report no conflicts of interest in this work.

\section{References}

1. Au WY, Weisenburger DD, Intragumtornchai T, et al. Clinical differences between nasal and extranasal natural killer/T-cell lymphoma: a study of 136 cases from the International Peripheral T-Cell Lymphoma Project. Blood. 2009;113(17):3931-3937. doi:10.1182/ blood-2008-10-185256

2. Fox CP, Haigh TA, Taylor GS, et al. A novel latent membrane 2 transcript expressed in Epstein-Barr virus-positive NK- and T-cell lymphoproliferative disease encodes a target for cellular immunotherapy. Blood. 2010;116(19):3695-3704. doi:10.1182/ blood-2010-06-292268

3. Vose J, Armitage J, Weisenburger D. International TCLP. International peripheral T-cell and natural killer/T-cell lymphoma study: pathology findings and clinical outcomes. J Clin Oncol. 2008;26(25):4124-4130.

4. Kwong YL, Kim WS, Lim ST, et al. SMILE for natural killer/T-cell lymphoma: analysis of safety and efficacy from the Asia Lymphoma Study Group. Blood. 2012;120(15):2973-2980. doi:10.1182/blood2012-05-431460

5. Yamaguchi M, Kwong YL, Kim WS, et al. Phase II study of SMILE chemotherapy for newly diagnosed stage IV, relapsed, or refractory extranodal natural killer (NK)/T-cell lymphoma, nasal type: the NK-Cell Tumor Study Group study. J Clin Oncol. 2011;29 (33):4410-4416. doi:10.1200/JCO.2011.35.6287

6. Ishida Y, Agata Y, Shibahara K, Honjo T. Induced expression of PD-1, a novel member of the immunoglobulin gene superfamily, upon programmed cell death. EMBO J. 1992;11(11):3887-3895. doi:10.1002/embj.1992.11.issue-11

7. Dong H, Zhu G, Tamada K, Chen L. B7-H1, a third member of the B7 family, co-stimulates T-cell proliferation and interleukin-10 secretion. Nat Med. 1999;5(12):1365-1369. doi:10.1038/70932

8. Latchman Y, Wood CR, Chernova T, et al. PD-L2 is a second ligand for PD-1 and inhibits T cell activation. Nat Immunol. 2001;2 (3):261-268. doi:10.1038/85330

9. Okazaki T, Honjo T. PD-1 and PD-1 ligands: from discovery to clinical application. Int Immunol. 2007;19(7):813-824. doi:10.1093/ intimm/dxm057

10. Dong H, Strome SE, Salomao DR, et al. Tumor-associated B7-H1 promotes T-cell apoptosis: a potential mechanism of immune evasion. Nat Med. 2002;8(8):793-800. doi:10.1038/nm730
11. Karwacz K, Bricogne C, MacDonald D, et al. PD-L1 co-stimulation contributes to ligand-induced $\mathrm{T}$ cell receptor down-modulation on CD8+ T cells. EMBO Mol Med. 2011;3(10):581-592. doi:10.1002/ emmm.v3.10

12. Eto S, Yoshikawa K, Nishi M, et al. Programmed cell death protein 1 expression is an independent prognostic factor in gastric cancer after curative resection. Gastric Cancer. 2016;19(2):466-471. doi:10.10 07/s10120-015-0519-7

13. Massi D, Brusa D, Merelli B, et al. The status of PD-L1 and tumor-infiltrating immune cells predict resistance and poor prognosis in BRAFi-treated melanoma patients harboring mutant BRAFV600. Ann Oncol. 2015;26(9):1980-1987. doi:10.1093/annonc/mdv255

14. Qin T, Zeng YD, Qin G, et al. High PD-L1 expression was associated with poor prognosis in 870 Chinese patients with breast cancer. Oncotarget. 2015;6(32):33972-33981. doi:10.18632/oncotarget.5583

15. Ohigashi Y, Sho M, Yamada Y, et al. Clinical significance of programmed death-1 ligand-1 and programmed death-1 ligand-2 expression in human esophageal cancer. Clin Cancer Res. 2005;11 (8):2947-2953. doi:10.1158/1078-0432.CCR-04-1469

16. Thompson RH, Kuntz SM, Leibovich BC, et al. Tumor B7-H1 is associated with poor prognosis in renal cell carcinoma patients with long-term follow-up. Cancer Res. 2006;66(7):3381-3385. doi:10.11 58/0008-5472.CAN-05-4303

17. Azuma K, Ota K, Kawahara A, et al. Association of PD-L1 overexpression with activating EGFR mutations in surgically resected nonsmall-cell lung cancer. Ann Oncol. 2014;25(10):1935-1940. doi:10.1093/annonc/mdu242

18. Kim WY, Jung HY, Nam SJ, et al. Expression of programmed cell death ligand 1 (PD-L1) in advanced stage EBV-associated extranodal $\mathrm{NK} / \mathrm{T}$ cell lymphoma is associated with better prognosis. Virchows Arch. 2016;469(5):581-590. doi:10.1007/s00428-016-2011-0

19. Bi XW, Wang H, Zhang WW, et al. PD-L1 is upregulated by EBV-driven LMP1 through NF-kappaB pathway and correlates with poor prognosis in natural killer/T-cell lymphoma. J Hematol Oncol. 2016;9(1):109. doi:10.1186/s13045-016-0341-7

20. Nagato T, Ohkuri T, Ohara K, et al. Programmed death-ligand 1 and its soluble form are highly expressed in nasal natural killer/ T-cell lymphoma: a potential rationale for immunotherapy. Cancer Immunol Immunother. 2017;66(7):877-890. doi:10.1007/s00262017-1987-x

21. Jo JC, Kim M, Choi Y, et al. Expression of programmed cell death 1 and programmed cell death ligand 1 in extranodal NK/T-cell lymphoma, nasal type. Ann Hematol. 2017;96(1):25-31. doi:10.1007/ s00277-016-2818-4

22. Muhamad H, Suksawai N, Assanasen T, Polprasert C, Bunworasate U, Wudhikarn K. Programmed cell death 1 and Programmed cell death ligands in extranodal natural killer/T Cell Lymphoma: expression Pattern and potential prognostic relevance. Acta Haematol. 2019;143(1):1-11.

23. Wolf D, Wolf AM, Rumpold H, et al. The expression of the regulatory $\mathrm{T}$ cell-specific forkhead box transcription factor FoxP3 is associated with poor prognosis in ovarian cancer. Clin Cancer Res. 2005;11(23):8326-8331. doi:10.1158/1078-0432.CCR-05-1244

24. Yagi H, Nomura T, Nakamura K, et al. Crucial role of FOXP3 in the development and function of human $\mathrm{CD} 25+\mathrm{CD} 4+$ regulatory $\mathrm{T}$ cells. Int Immunol. 2004;16(11):1643-1656. doi:10.1093/intimm/dxh165

25. Campbell DJ, Ziegler SF. FOXP3 modifies the phenotypic and functional properties of regulatory T cells. Nat Rev Immunol. 2007;7 (4):305-310. doi:10.1038/nri2061

26. Watanabe MA, Oda JM, Amarante MK, Cesar Voltarelli J. Regulatory $\mathrm{T}$ cells and breast cancer: implications for immunopathogenesis. Cancer Metastasis Rev. 2010;29(4):569-579. doi:10.1007/s10555010-9247-y

27. Schott AK, Pries R, Wollenberg B. Permanent up-regulation of regulatory T-lymphocytes in patients with head and neck cancer. Int J Mol Med. 2010;26(1):67-75. doi:10.3892/ijmm_00000436 
28. Cabrera R, Ararat M, Xu Y, et al. Immune modulation of effector $\mathrm{CD} 4+$ and regulatory $\mathrm{T}$ cell function by sorafenib in patients with hepatocellular carcinoma. Cancer Immunol Immunother. 2013;62 (4):737-746. doi:10.1007/s00262-012-1380-8

29. Carreras J, Lopez-Guillermo A, Fox BC, et al. High numbers of tumor-infiltrating FOXP3-positive regulatory $\mathrm{T}$ cells are associated with improved overall survival in follicular lymphoma. Blood. 2006;108(9):2957-2964. doi:10.1182/blood-2006-04-018218

30. Alvaro T, Lejeune M, Salvado MT, et al. Outcome in Hodgkin's lymphoma can be predicted from the presence of accompanying cytotoxic and regulatory $\mathrm{T}$ cells. Clin Cancer Res. 2005;11 (4):1467-1473. doi:10.1158/1078-0432.CCR-04-1869

31. Tzankov A, Meier C, Hirschmann P, Went P, Pileri SA, Dirnhofer S. Correlation of high numbers of intratumoral FOXP3+ regulatory $\mathrm{T}$ cells with improved survival in germinal center-like diffuse large B-cell lymphoma, follicular lymphoma and classical Hodgkin's lymphoma. Haematologica. 2008;93(2):193-200. doi:10.3324/haematol. 11702

32. Francisco LM, Salinas VH, Brown KE, et al. PD-L1 regulates the development, maintenance, and function of induced regulatory $\mathrm{T}$ cells. J Exp Med. 2009;206(13):3015-3029. doi:10.1084/jem.2009 0847

33. Wilcox RA, Feldman AL, Wada DA, et al. B7-H1 (PD-L1, CD274) suppresses host immunity in T-cell lymphoproliferative disorders. Blood. 2009;114(10):2149-2158. doi:10.1182/blood-2009-04-216671

34. Shipp MA. International Non-Hodgkin's Lymphoma Prognostic Factors P. A predictive model for aggressive non-Hodgkin's lymphoma. N Engl J Med. 1993;329(14):987-994.
35. Lee J, Suh C, Park YH, et al. Extranodal natural killer T-cell lymphoma, nasal-type: a prognostic model from a retrospective multicenter study. J Clin Oncol. 2006;24(4):612-618. doi:10.1200/ JCO.2005.04.1384

36. Kim SJ, Yoon DH, Jaccard A, et al. A prognostic index for natural killer cell lymphoma after non-anthracycline-based treatment: a multicentre, retrospective analysis. Lancet Oncol. 2016;17 (3):389-400. doi:10.1016/S1470-2045(15)00533-1

37. Cheson BD. The International Harmonization Project for response criteria in lymphoma clinical trials. Hematol Oncol Clin North Am. 2007;21(5):841-854. doi:10.1016/j.hoc.2007.06.011

38. Green MR, Monti S, Rodig SJ, et al. Integrative analysis reveals selective 9p24.1 amplification, increased PD-1 ligand expression, and further induction via JAK2 in nodular sclerosing Hodgkin lymphoma and primary mediastinal large B-cell lymphoma. Blood. 2010;116(17):3268-3277. doi:10.1182/blood-2010-05-282 780

39. Kiyasu J, Miyoshi H, Hirata A, et al. Expression of programmed cell death ligand 1 is associated with poor overall survival in patients with diffuse large B-cell lymphoma. Blood. 2015;126(19):2193-2201. doi:10.1182/blood-2015-02-629600

40. Azuma T, Yao S, Zhu G, Flies AS, Flies SJ, Chen L. B7-H1 is a ubiquitous antiapoptotic receptor on cancer cells. Blood. 2008;111 (7):3635-3643. doi:10.1182/blood-2007-11-123141

41. Kwong YL, Chan TSY, Tan D, et al. PD1 blockade with pembrolizumab is highly effective in relapsed or refractory NK/T-cell lymphoma failing 1-asparaginase. Blood. 2017;129(17):2437-2442. doi:10.1182/ blood-2016-12-756841

\section{Publish your work in this journal}

Cancer Management and Research is an international, peer-reviewed open access journal focusing on cancer research and the optimal use of preventative and integrated treatment interventions to achieve improved outcomes, enhanced survival and quality of life for the cancer patient.
The manuscript management system is completely online and includes a very quick and fair peer-review system, which is all easy to use. Visit http://www.dovepress.com/testimonials.php to read real quotes from published authors. 